\title{
Modeling of Us Dollar to Euro Rate Dependence on USA GDP Dynamics
}

\author{
Shkodinsky S. V. ${ }^{1}, \&$ Prodchenko I. A. ${ }^{2}$ \\ ${ }^{1}$ Doctor of economics, professor, department head at the State Research Institute of System Analysis of the \\ Accounts Chamber of the Russian Federation, Moscow, Russia \\ ${ }^{2}$ Ph.D., associate professor, senior researcher at the State Research Institute of System Analysis of the Accounts \\ Chamber of the Russian Federation, Moscow, Russia \\ Correspondence: Shkodinsky S. V., Doctor of economics, professor, department head at the State Research \\ Institute of System Analysis of the Accounts Chamber of the Russian Federation, Moscow, Russia. E-mail: \\ sh-serg@bk.ru
}

Received: January 3, 2015

Accepted: February 3, $2015 \quad$ Online Published: July 30, 2015

doi:10.5539/mas.v9n8p277

URL: http://dx.doi.org/10.5539/mas.v9n8p277

\begin{abstract}
The article analyzes the changes in the USD, to evaluate the influence of gross domestic product in the United States the value of the United States dollar, the influence of gross domestic product of the United States on the value of the United States dollar against the euro, the models of the linear dependence of the USD against the European currency, raschetan coefficient of pair of linear correlation, characterizing the degree of dependence of the United States dollar against the euro on the dynamics of the index of real GDP in the United States of a linear model.
\end{abstract}

Keywords: modeling, exchange rate, exchange rate changes, the gross domestic product, the United States, the euro, the index, a linear function

\section{Introduction}

It is known that the exchange climate of the state takes important effect on the economic, investment and social processes in the society (Aleksandrovich JA, 2005). And one of the significant challenges of the exchange policy is to implement the concerted actions of different states in the interest of macroeconomic regulation and ensuring the currency markets stability (Ivanter A., Peresetsky A., 1999). Many economists try to reveal regularities of exchange rates formation, which in its turn forms the basis for decision-making to overcome the crisis developments in the economy and for financial losses minimizing (Balatsky EV, 2005; OA Gulyaev, 2008; P. Kryukov A. 2011; Panilov MA, 2009; Bogoviz AV, 2013).

However, the problem of forecasting and modeling of exchange rates also is a complex multifactorial problem to which the focused attention of scientists and specialists is paid. Thus, in the P.A. Kryukov's work "The methodology of the exchange rate dynamics modeling" an overview of modern empirical research of currency market analyzing and forecasting methods and description of a new methodological approach to the modeling of exchange rate dynamics from the perspective of solving the problem of the classifivcation of its conditions by methods of factor scaling and logistic regression is provided (Kryukov, P.A., 2011). The study of E. Balatsky "The exchange rates formation factors: pluralism of patterns, theories and conceptions", which presents an analysis of the analytical material accumulated in this area, is also interesting (Balatsky E., 2010).

The urgency of the chosen theme of the scientific article is conditioned, firstly, by the manifestation of the violent fluctuations in the US dollar against major world currencies, especially agains the backdrop of the negative effects of the global financial and economic crisis; secondly, by the lack of a mechanism for determining the degree of influence of the US gross domestic product dynamics on the US dollar value against major world currencies; thirdly, by the need to improve the practice of analysis of the factors affecting the change in the US dollar value against major world currencies (P.A. Kryukov, V. Kryukov, 2011).

2. Method. Gross Domestic Product of the United States is the main indicator, which reflects the condition of the national economy (Buglaev V.B., Liventsev N.N., 1998). It represents the market value of the goods and services produced during a certain period, including the income of foreign corporations and non-residents working in the 
USA, and excluding the revenues of American citizens and companies, received abroad.

Within the period from January 1, 1999 to April 1, 2011 gross domestic product of the United States increased by 2934.3 billion US dollars (27.9 percent).

The diagram of the US gross domestic product dynamics for the period of from January 1, 1999 to April 1, 2011 is shown in the Figure1.

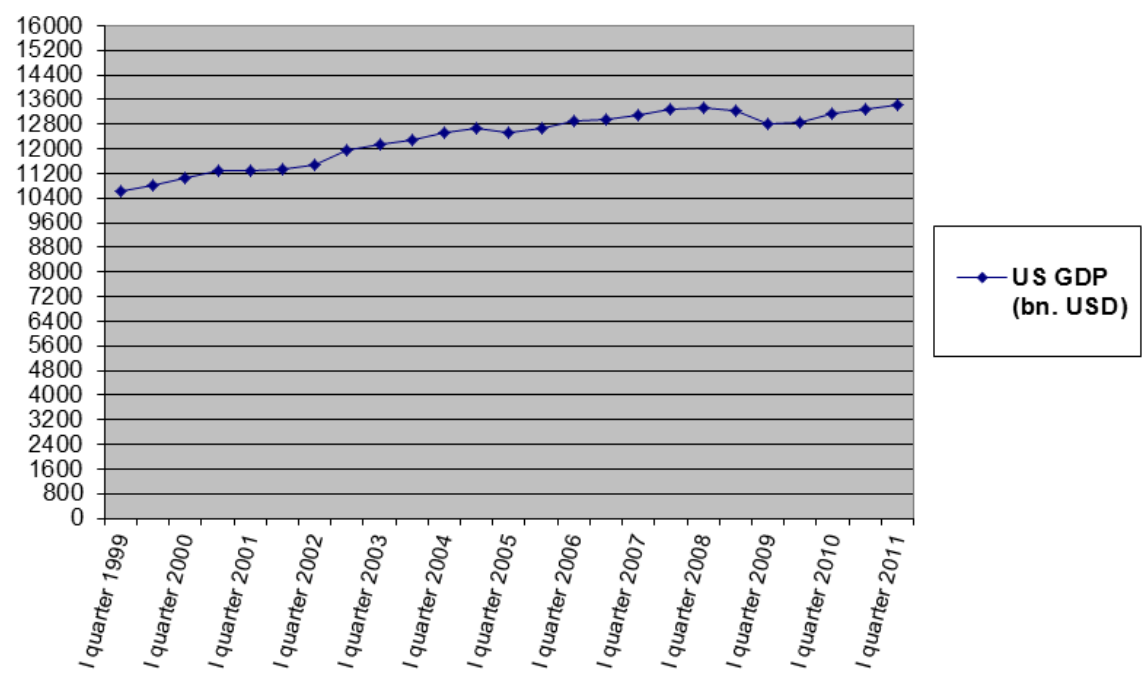

Figure 1. The US gross domestic product dynamics for the period of from January 1, 1999 to April 1, 2011

For the IV quarter of 1998 gross domestic product of the United States was 10507.6 bln US dollars. For the I. quarter of 2011 the US gross domestic product was 13441.9 bln US dollars.

The dynamics of US gross domestic product (hereinafter - GDP) during the concerned period is presented in the Table 1.

Table 1. US gross domestic product change dynamics for the period of from January 1, 1999 to April 1, 2011 (Note 1)

\begin{tabular}{cccc}
\hline Period & $\begin{array}{c}\text { Value } \\
\text { bln. of USD }\end{array}$ & Change & Publication date \\
\hline I quarter 11 & 13441.9 & 61.2 & 26.05 .2011 \\
IV quarter 10 & 13380.7 & 102.2 & 25.03 .2011 \\
III quarter 10 & 13278.5 & 83.6 & 22.12 .2010 \\
II quarter10 & 13194.9 & 56.1 & 30.09 .2010 \\
I quarter 10 & 13138.8 & 119.8 & 25.06 .2010 \\
IV quarter 09 & 13019 & 158.2 & 26.03 .2010 \\
III quarter 09 & 12860.8 & 50.8 & 22.12 .2009 \\
II quarter 09 & 12810 & -22.6 & 30.09 .2009 \\
I quarter 09 & 12832.6 & -161.1 & 25.06 .2009 \\
IV quarter 08 & 12993.7 & -229.8 & 26.03 .2009 \\
III quarter 08 & 13223.5 & -135.5 & 23.12 .2008 \\
II quarter 08 & 13359 & 19.8 & 26.09 .2008 \\
I quarter 08 & 13339.2 & -24.3 & 29.05 .2008 \\
IV quarter 07 & 13363.5 & 95.0 & 27.03 .2008 \\
III quarter 07 & 13268.5 & 74.4 & 30.01 .2008 \\
II quarter 07 & 13194.1 & 104.8 & 30.09 .2007 \\
I quarter 07 & 13089.3 & 28.6 & 29.06 .2007 \\
IV quarter 06 & 13060.7 & 94.8 & 30.03 .2007 \\
III quarter 06 & 12965.9 & 3.4 & 29.12 .2006 \\
II quarter 06 & 12962.5 & 46.6 & 29.09 .2006 \\
\hline
\end{tabular}




\begin{tabular}{cccc}
\hline I quarter 06 & 12915.9 & 167.2 & 30.06 .2006 \\
IV quarter 05 & 12748.7 & 65.5 & 31.03 .2006 \\
III quarter 05 & 12683.2 & 95.7 & 30.12 .2005 \\
II quarter 05 & 12587.5 & 53.4 & 30.09 .2005 \\
I quarter 05 & 12534.1 & 123.8 & 30.06 .2005 \\
IV quarter 04 & 12410.3 & 106.8 & 31.03 .2005 \\
III quarter 04 & 12303.5 & 89.7 & 31.12 .2004 \\
II quarter 04 & 12213.8 & 86.2 & 30.09 .2004 \\
I quarter 04 & 12127.6 & 84.8 & 30.06 .2004 \\
IV quarter 03 & 12042.8 & 107.3 & 31.03 .2004 \\
III quarter 03 & 11935.5 & 196.8 & 31.12 .2003 \\
II quarter 03 & 11738.7 & 92.9 & 30.09 .2003 \\
I quarter 03 & 11645.8 & 47.0 & 30.06 .2003 \\
IV quarter 02 & 11598.8 & 2.4 & 31.03 .2003 \\
III quarter 02 & 11596.4 & 57.6 & 31.12 .2002 \\
II quarter 02 & 11538.8 & 60.9 & 30.09 .2002 \\
I quarter 02 & 11477.9 & 97.8 & 28.06 .2002 \\
IV quarter 01 & 11380.1 & 40.0 & 29.03 .2002 \\
III quarter 01 & 11340.1 & -31.2 & 31.12 .2001 \\
II quarter 01 & 11371.3 & 74.1 & 28.09 .2001 \\
I quarter 01 & 11297.2 & -37.3 & 29.06 .2001 \\
IV quarter 00 & 11334.5 & 66.6 & 30.03 .2001 \\
III quarter 00 & 11267.9 & 9.4 & 29.12 .2000 \\
II quarter 00 & 11258.5 & 215.5 & 29.09 .2000 \\
I quarter 00 & 11043.0 & 28.7 & 30.06 .2000 \\
IV quarter 99 & 11014.3 & 194.4 & 31.03 .2000 \\
III quarter 99 & 10819.9 & 135.9 & 31.12 .1999 \\
II quarter 99 & 10684 & 82.8 & 30.09 .1999 \\
I quarter 99 & 10601.2 & 93.6 & 30.06 .1999 \\
IV quarter 98 & 10507.6 & 178.8 & 31.03 .1999 \\
\hline & & & \\
\hline
\end{tabular}

As of January 1, 1999, the exchange rate of US dollar to euro was 0.8572 euro for 1 US dollar at a value of GDP of the Uniated States for the IV quarter 1998 of USD 10507.6 billion.

For the IV quarter of 1999, GDP of the United States reached the value of USD $11014.3 \mathrm{bln}$, while the the rate of US dollar to euro was 0.992647 euro for 1 US dollar as of January 1, 2000.

As of January 1, 2001, the rate of US dollar to euro was 1.051138 euro for 1 US dollar at the value USA GDP for the IV quarter of 2000 of USD 11334.5 bln.

For the IV quarter of 2001, GDP of the United States increased insignificantly and reached the value of USD 11 380.1 billion, while the rate of US dollar to euro was 1.132245 euro per 1 US dollar as of January 1, 2002.

Then, with a slight increase of GDP of the United States a decline of the rate US dollar to euro was observed. For the IV quarter of 2002 the GDP of the United States reached the value of USD 11598.8 billion, while the rate of US dollar to euro fell to 0.955293 euros for 1 US dollar as of January 1, 2003. As of January 1, 2004, the rate of US dollar to euro fell to 0.793967 euros for 1 US dollar, while the value of GDP of the United States for the IV quarter 2003 was USD 12042.8 billion.

For the IV quarter of 2004 the GDP of the United States reached the value of USD 12410.3 billion, while the rate of US dollar to euro continued to fall to EUR 0.733299 per 1 US dollar as of January 1, 2005. As of January 1, 2006, the rate of US dollar to euro was sterengthened to 0.829531 euros per 1 US dollar, while the GDP of the United States for the IV quarter 2005 was USD 12748.7 billlion.

For the IV quarter of 2006, of the GDP of the United States reached the value of USD 13 060.7, while the rate of US dollar to euro fell to 0.766872 euros per 1 US dollar as of January 1, 2007.

As of January 1, 2008, the rate of US dollar to euro fell to the record lowest value of USD 0.679302 euros per 1 US dollar, while the GDP of the United States for the IV quarter of 2007, was USD 13363.5 billion. For the IV quarter of 2008 GDP of the United States for the first time during the concerned period fell to USD 12993.7 
billion, while the rate of US dollar to euro was 0.709471 euro per 1 US dollar as of January 1, 2009.

As of January 1, 2010, the rate of US dollar to euro fell to 0.694541 euros per 1 US dollar, while the GDP of the United States for the IV quarter 2009 was USD 133019.0 billion. For the IV quarter of 2010, the GDP of the United States reached the value USD 13380.7 billion, while the rate of US dollar to euro was 0.749625 euro per 1 US dollar as of 1 January 2011.

Dynamics of change in the GDP of USA and the rate of US dollar to euro during the period of January 1, 1999 to April 1, 2011 is presented in the Table 2.

Table 2. Dynamics of change in the GDP of USA and the rate of US dollar to euro during the period of January 1,1999 to April 1, 2011

\begin{tabular}{|c|c|c|c|}
\hline $\mathrm{n}$ & date & USD/EUR & GDP of USA in bln. of \$ (GDPi) \\
\hline 1 & 01.01 .1999 & 0.857202 & 10507.6 \\
\hline 2 & 01.04.1999 & 0.932099 & 10601.2 \\
\hline 3 & 01.07.1999 & 0.967626 & 10684.0 \\
\hline 4 & 01.10 .1999 & 0.93961 & 10819.9 \\
\hline 5 & 01.01 .2000 & 0.992647 & 11014.3 \\
\hline 6 & 01.04 .2000 & 1.043796 & 11043.0 \\
\hline 7 & 01.07 .2000 & 1.049775 & 11258.5 \\
\hline 8 & 03.10 .2000 & 1.13445 & 11267.9 \\
\hline 9 & 04.01 .2001 & 1.051138 & 11334.5 \\
\hline 10 & 03.04 .2001 & 1.140309 & 11297.2 \\
\hline 11 & 03.07.2001 & 1.180567 & 11371.3 \\
\hline 12 & 02.10 .2001 & 1.099365 & 11340.1 \\
\hline 13 & 01.01 .2002 & 1.132245 & 11380.1 \\
\hline 14 & 02.04 .2002 & 1.144033 & 11477.9 \\
\hline 15 & 02.07 .2002 & 1.005632 & 11538.8 \\
\hline 16 & 01.10 .2002 & 1.017398 & 11596.4 \\
\hline 17 & 01.01 .2003 & 0.955293 & 11598.8 \\
\hline 18 & 01.04 .2003 & 0.923447 & 11645.8 \\
\hline 19 & 01.07 .2003 & 0.874968 & 11738.7 \\
\hline 20 & 01.10 .2003 & 0.859846 & 11935.5 \\
\hline 21 & 01.01 .2004 & 0.793967 & 12042.8 \\
\hline 22 & 01.04 .2004 & 0.81686 & 12127.6 \\
\hline 23 & 01.07 .2004 & 0.827814 & 12213.8 \\
\hline 24 & 01.10 .2004 & 0.81103 & 12303.5 \\
\hline 25 & 01.01 .2005 & 0.733299 & 12410.3 \\
\hline 26 & 01.04 .2005 & 0.773156 & 12534.1 \\
\hline 27 & 01.07 .2005 & 0.826788 & 12587.5 \\
\hline 28 & 01.10 .2005 & 0.831739 & 12683.2 \\
\hline 29 & 11.01 .2006 & 0.829531 & 12748.7 \\
\hline 30 & 01.04 .2006 & 0.823724 & 12915.9 \\
\hline 31 & 01.07 .2006 & 0.786905 & 12962.5 \\
\hline 32 & 03.10 .2006 & 0.788892 & 12965.9 \\
\hline 33 & 10.01 .2007 & 0.766872 & 13060.7 \\
\hline 34 & 03.04 .2007 & 0.748896 & 13089.3 \\
\hline 35 & 03.07 .2007 & 0.738552 & 13194.1 \\
\hline 36 & 02.10 .2007 & 0.701901 & 13268.5 \\
\hline 37 & 10.01 .2008 & 0.679302 & 13363.5 \\
\hline 38 & 01.04 .2008 & 0.633713 & 13339.2 \\
\hline 39 & 01.07 .2008 & 0.633112 & 13359.0 \\
\hline 40 & 01.10 .2008 & 0.69512 & 13223.5 \\
\hline 41 & 01.01 .2009 & 0.709471 & 12993.7 \\
\hline 42 & 01.04 .2009 & 0.755173 & 12832.6 \\
\hline 43 & 01.07 .2009 & 0.707814 & 12810.0 \\
\hline
\end{tabular}




\begin{tabular}{llll}
\hline 44 & 01.10 .2009 & 0.683761 & 12860.8 \\
45 & 01.01 .2010 & 0.694541 & 13019.0 \\
46 & 01.04 .2010 & 0.745379 & 13138.8 \\
47 & 01.07 .2010 & 0.817996 & 13194.9 \\
48 & 01.10 .2010 & 0.736322 & 13278.5 \\
49 & 01.01 .2011 & 0.749625 & 13380.7 \\
50 & 01.04 .2011 & 0.706065 & 13441.9 \\
\hline
\end{tabular}

In the Figure 2 the diagram of the dynamics of changes in exchange ratios of the US dollar to euro during the studied period.

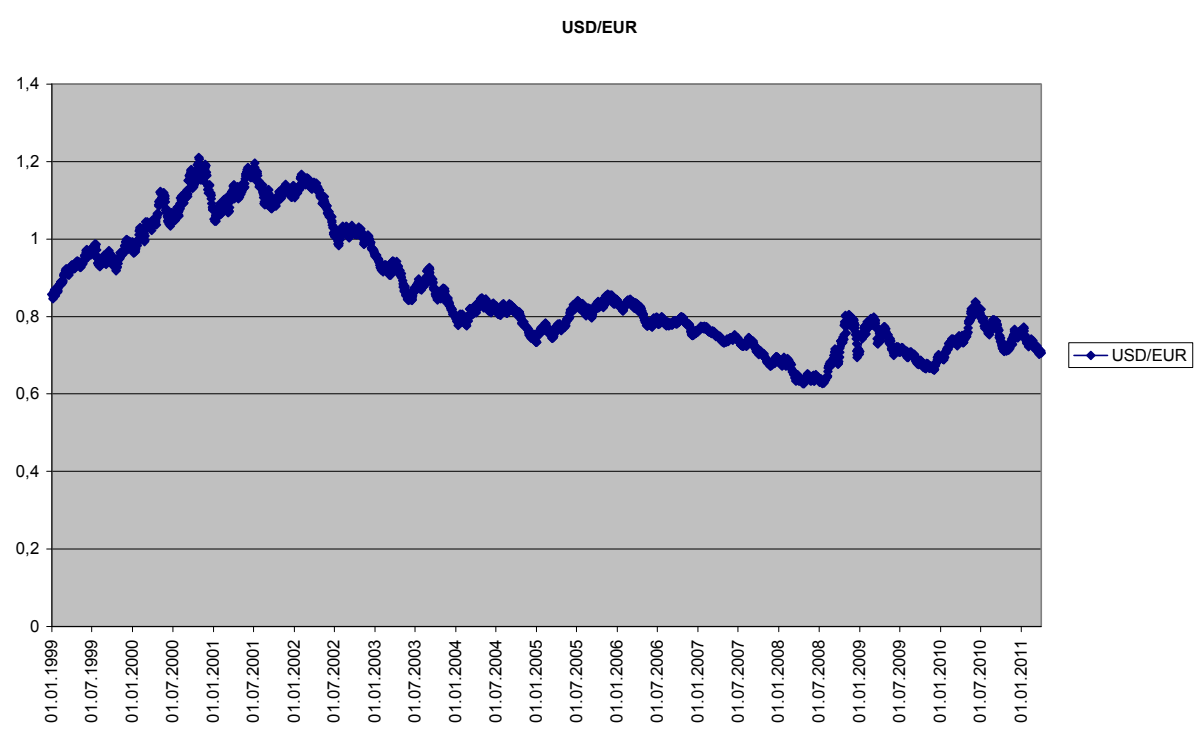

Figure 2. The diagram of the dynamics of changes of the exchange ratios of the US dollar to Euro for the period of from January 1, 1999 to April 1, 2011

The diagram of dynamics of GDP in the United Sates and exchange ratios of US dollar to euro in the concerned period is presented in the Figure 3.

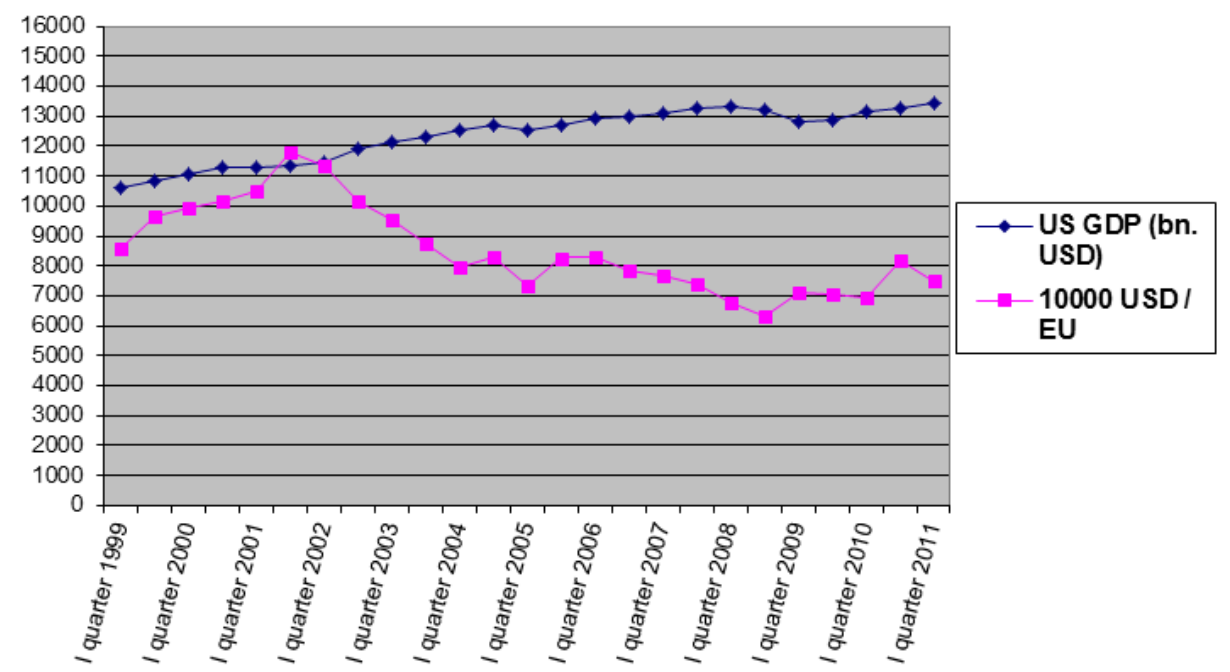

Figure 3. The diagram of dynamics of GDP in the United Sates and exchange ratios of US dollar to euro fo the period of from January 1, 1999 to April 1, 2011

Let's consider the dependence of the exchange ratios of US dollar to Euro on the index of the real GDP of the 
United States. Nominal GDP (absolute) is expressed in current prices of the given year. Real GDP (as adjusted for inflation) is expressed in the prices of the previous or any other base year. To what extent the growth of GDP is determined by the growth of production, rather than by growth of prices is considered in the real GDP (Perron P., 1997).

The diagram of index dynamecs of real GDP of the United States and exchange ratios of US dollar to Euro in the concerned period is presented in the Figure 4.

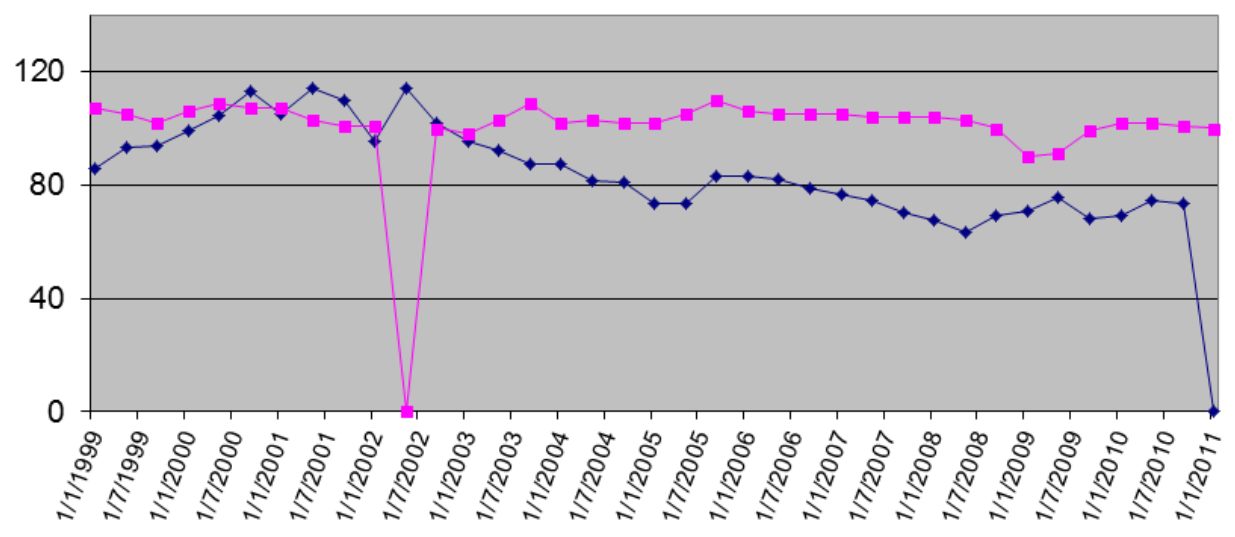

$$
\multimap 100 \text { USD / EUR } \rightarrow \text { index of the real US GDP }
$$

Figure 4. The diagram of index dynamecs of real GDP of the United States and exchange ratios of US dollar to Euro for the period of from January 1, 1999 to April 1, 2011

We noted above that the gross domestic product, GDP, is a general index of amount of added values created during a certain period by all manufacturers acting in the territory of the country. GDP is a generalizing indicator of the power of the economy (or vice versa, its weakness during recessions) (Pugel T.A., Lindert P.H, 2003). Its connection with the exchange rate is always obvious: the stronger GDP grows, the stronger domestic currency is. The higher the GDP is, the better the economic situation. It is one of the main indicators for the currency markets Reaction on the publication of not only growth indicators of the main economies, but their corrected (specified) values can be very significant.

According to the quantitative theory, the growth of the country national income as a result of new goods sales leads to increased demand for transactions with the national currency (Kravtsov MA, Miksjuk SF, 2005).

National income is not an independent component, which can be changed on its own. What causes the change of national income has a great impact on the exchange rate (Keynes, 1999). Increase of the offers of goods and servicest to foreign markets made by a country leads to an increase in the national currency. The increase of national income due to additional expences of government may not cause an increase of the national currency, especially if the additional money will be used to increase imports (Fedoseev V.V, Garmash A.N \& others, 2005).

Thus, much depends on what causes the change in the national income: an increase in the ability of the goods supply (currency rate increases) or an increase in domestic demand (the exchange rate falls) (Litinskii D.S., 2003).

The proposed mechanism for determination of the extent of influence of the USA GDP dynamics on the value of the rate of US dollar to Euro consists of two stages. At the first stage the model of linear dependence of the rate of US dollar to Euro on the dynamics of the GDP of the United States. At the second stage the extent of influence the the USA GDP dynamics on the value of the rate of US dollar to Euro by calculating the coefficient of pair linear correlation characterizing the closeness of dependency of the rate of US dollar to Euro on the dynamics of GDP of the United States on the model developed of the the first stage (Shelobaev S.I., 2005).

To define the mechanism for determination of the extent of the influence of the dynamics of the USA GDP on the value of the rate of US dollar to Euro, let's consider the statistical series of USA GDP and the exchange ratios of the US dollar (USD) to Euro during the analyzed period, on the basis of data obtained from the official website of Bank of Russia www.cbr. ru, as well as from the site www.quote.ru and www.prime-tass.ru. 
One of the mathematical methods serving to align different statistical series is the method of least squares. It reduces to the fact that the existing dependence is modeled by some production function, the parameters of which are determined at the same time (Malihin V.I., 1999).

The main requirement of the least squares method consists in the fact that the sum of squared deviations of the calculated (theoretical) levels of the actual values of the dependent factor should be the lowest (minimum) (Johansen S., 2000; Oskorbin N.M., 1989).

We present the dependence of the US dollar rate on the dynamics of the GDP of the United States in the form of the production function in the following form:

$$
\text { Yri }=f(\mathrm{GDPi})
$$

where: Yri is a calculated value of the US dollar rate;

GDPi is the GDP of the United States.

After we denote the sum of squared deviations of the calculated (theoretical) levels of the actual values of the dependent indication by S, let's write the main requirement of this method in mathematical form.

$$
\mathrm{S}=\sum(f(\mathrm{GDPi})-\mathrm{Yi})^{2} \rightarrow \min
$$

where: $\mathrm{Yi}$ is the actual meaning of the rate of US dollar;

Since GDPi and Yi are known values, then the sum of squares of the specified values of deviations depends on the parameters a0, al which are determined. Therefore we can write that the $\mathrm{S}$ sum is a function of the known parameters:

$$
\mathrm{S}=f(\mathrm{a} 0, \mathrm{a} 1)
$$

At the point of extremum of the differentiable function its first derivative is equal to zero. The function (3) is differentiable. $\mathrm{S}$ is minimal, that is extremal. Therefore, we can take the partial derivatives sums of $\mathrm{S}$ under certain parameters and equate them to zero.

$$
\frac{\delta S}{\delta a 0}=0 ; \frac{\delta S}{\delta a 1}=0
$$

As a result the two equations with two determinate parameters will be obtained. The range of equations (4) constitutes the system of so-called normal equations. While solving the system of normal equations unknown parameters of the production function are found. Systems of these equations are solved by any known method (method of substitution, addition, by G. Cramer's method (Muraviev D.G., 2006), etc.). Available parameters are recorded in the the sought-for function production function (Grishin A.F., Kotov-Darty S.F., Yagunov V.N., 2005).

Since the increase of the GDP in the United States causes the growth of the the national currency rate (unless other rate forming factors counteract more) when determining the dependence of the exchange ratios of the US dollar to the European currency, we use a linear model of dependence of the rate of US dollar on the size of the GDP of the United States.

Linear function, which models the variation of the currency rate (Yi), depending on the dynamics of GDP GBPi, has the form:

$$
\mathrm{Yi}=\mathrm{a} 0+\mathrm{a} 1{ }^{*} \mathrm{GBPi}
$$

Then the main requirement of the least squares method, according to which the sum of the squares of deviations between the calculated and actual levels shall be minimal (Bendat J., Peirsol A., 1989), can be presented in the following form:

$$
\mathrm{S}=\sum\left(\mathrm{a} 0+\mathrm{a} 1{ }^{*} \mathrm{GBPi}-\mathrm{Yi}\right)^{2} \rightarrow \min
$$

In equation (5) two parameters shall be determined: а0 и а1. Therefore, the partial derivatives of the $\mathrm{S}$ sum are written (6), under the parameters a0 and a1 and they are equated to zero.

$$
\frac{\delta S}{\delta a 0}=2 \sum\left(a 0+a 1 * G B P_{i}-Y_{i}\right) * 1=0
$$




$$
\frac{\delta s}{\delta a 1}=2 \sum\left(a 0+a 1 * G B P_{i}-Y_{i}\right) * 1=0
$$

after trimming the both equation by 2 , opening the brackets and making a term-by-term summation, we will obtain:

$$
\begin{aligned}
& \sum \mathrm{a} 0+\sum \mathrm{a} 1 * \mathrm{GBPi}-\sum \mathrm{Yi}=0, \\
& \sum \mathrm{a} 0 * \mathrm{GBPi}+\sum \mathrm{a} 1 * \mathrm{GBPi}^{2}-\sum \mathrm{Yi} * \mathrm{GBPi}=0
\end{aligned}
$$

Since Yi and GBPi are known amounts, the $\Sigma Y_{i}$ and $\Sigma G B P_{i}$ are transferred to the right side of the equations. Since $\mathrm{a} 0$ and $\mathrm{a} 1$ are the parameters, which are in this case constant numbers, they are taken beyond the summation sign.

Therefore:

$$
\begin{aligned}
& \sum \mathrm{a} 0=\mathrm{n} * \mathrm{a} 0 \text {, where } \mathrm{n} \text { is the number of observations; } \\
& \qquad \begin{array}{l}
\sum \mathrm{a} 0 * \mathrm{GBPi}=\mathrm{a} 0 \sum \mathrm{GBPi} \\
\sum \mathrm{a} 1 * \mathrm{GBPi}^{2}=\mathrm{a} 1 \sum \mathrm{GBPi}^{2}
\end{array}
\end{aligned}
$$

Ultimately, the system of normal equations takes the form of:

$$
\begin{gathered}
\mathrm{n} * \mathrm{a} 0+\mathrm{a} 1 \sum \mathrm{GBPi}=\sum \mathrm{Yi} \\
\mathrm{a} 0 \sum \mathrm{GBPi}+\mathrm{a} 1 \sum \mathrm{GBPi}^{2}=\sum \mathrm{Yi}^{*} \mathrm{GBPi}
\end{gathered}
$$

Let's solve this system by the determinations (by Kramer's methos). The determinant of the system (9) has the following form:

$$
\Delta=\left|\begin{array}{cc}
\mathrm{n} & \sum \mathrm{GBP}_{\mathrm{i}} \\
\sum \mathrm{GBP}^{2} & \sum \mathrm{GBP}^{2}
\end{array}\right|=\mathrm{n} \sum \mathrm{GBP}^{2}-\left(\sum \mathrm{GBP}^{2}\right)^{2}
$$

The determinants for evaluation of $\mathrm{a} 0$ and $\mathrm{a} 1$ are:

$$
\begin{aligned}
& \Delta_{\mathrm{a} 0}=\left|\begin{array}{cc}
\sum \mathrm{Y}_{\mathrm{i}} & \sum \mathrm{GBP}_{\mathrm{i}} \\
\sum \mathrm{Y}_{\mathrm{i}} * \mathrm{GBP}_{\mathrm{i}} & \sum \mathrm{GBP}^{2}
\end{array}\right|=\sum \mathrm{GBP}^{2} \sum \mathrm{Y}_{\mathrm{i}}-\sum \mathrm{GBP}^{2} \sum \mathrm{Y}_{\mathrm{i}} * \mathrm{GBP}_{\mathrm{i}} \\
& \Delta_{\mathrm{a} 1}=\left|\begin{array}{cc}
\mathrm{n} & \sum \mathrm{Y}_{\mathrm{i}} \\
\sum \mathrm{GBP}_{\mathrm{i}} & \sum \mathrm{Y}_{\mathrm{i}} * \mathrm{GBP}_{\mathrm{i}}
\end{array}\right|=\mathrm{n} \sum \mathrm{Y}_{\mathrm{i}} * \mathrm{GBP}_{\mathrm{i}}-\sum \mathrm{GBP}_{\mathrm{i}} \sum \mathrm{Y}_{\mathrm{i}}
\end{aligned}
$$

As a result the required paramenters will be:

$$
\begin{aligned}
& \mathrm{a} 0=\frac{\Delta_{\mathrm{a} 0}}{\Delta}=\frac{\sum \mathrm{GBP}^{2} \sum \mathrm{Y}_{\mathrm{i}}-\sum \mathrm{GBP}_{\mathrm{i}} \sum \mathrm{Y}_{\mathrm{i}} * \mathrm{GBP}_{\mathrm{i}}}{\mathrm{n} \sum \mathrm{GBP}^{2}-\left(\sum \mathrm{GBP}_{\mathrm{i}}\right)^{2}} \\
& \mathrm{a}_{1}=\frac{\Delta_{\mathrm{a} 1}}{\Delta}=\frac{\mathrm{n} \sum \mathrm{Y}_{\mathrm{i}} * \mathrm{GBP}_{\mathrm{i}}-\sum \mathrm{GBP}_{\mathrm{i}} \sum \mathrm{Y}_{\mathrm{i}}}{\mathrm{n} \sum \mathrm{GBP}^{2}-\left(\sum \mathrm{GBP}_{\mathrm{i}}\right)^{2}}
\end{aligned}
$$

\section{Results}

As a result we will obtain: 


$$
\begin{gathered}
\mathrm{a} 0=\frac{\Delta_{\mathrm{a} 0}}{\Delta}=\frac{\sum \mathrm{GBP}^{2} \sum \mathrm{Yi}_{\mathrm{i}}-\sum \mathrm{GBP}_{\mathrm{i}} \sum \mathrm{Yi}_{\mathrm{i}} * \mathrm{GBP}_{\mathrm{i}}}{\mathrm{n} \sum \mathrm{GBP}^{2}-\left(\sum \mathrm{GBP}_{\mathrm{i}}\right)^{2}}= \\
=\frac{7550028534,30 * 42,8487-602288,4 * 519632,3027}{50 * 7550028534,3-(602288,4)^{2}}=0,7146 \\
\mathrm{a} 1=\frac{\Delta \mathrm{a} 1}{\Delta}=\frac{\mathrm{n} \sum \mathrm{Yi}_{\mathrm{i}} * \mathrm{GBP}_{\mathrm{i}}-\sum \mathrm{GBP}_{\mathrm{i}} \sum \mathrm{Y}_{\mathrm{i}}}{\mathrm{n} \sum \mathrm{GBP}^{2}-\left(\sum \mathrm{GBP}_{\mathrm{i}}\right)^{2}}= \\
=\frac{50 * 519632,302705-602288,4 * 42,8487}{50 * 7550028534,30-(602288,4)^{2}}=1,1816 \mathrm{E}-05
\end{gathered}
$$

The function, modeling dependence of the value of the rate of US Dollar to Euro (Yi $)^{\text {Euro }}$ on dynamics of GDP of the United states has the following form:

$$
Y i^{E u r}=a 0+a 1 * G B P_{i}=0,7146+1,1816 E-0,5 * G B P_{i}
$$

As a result we will obtain:

$$
\begin{gathered}
\mathrm{a} 0=\frac{\Delta \mathrm{a} 0}{\Delta}=\frac{\sum \mathrm{GBP}^{2} \sum \mathrm{Y}_{\mathrm{i}}-\sum \mathrm{GBP}_{\mathrm{i}} \sum \mathrm{Y}_{\mathrm{i}} * \mathrm{GBP}_{\mathrm{i}}}{\mathrm{n} \sum \mathrm{GBP}^{2}-\left(\sum \mathrm{GBP}_{\mathrm{i}}\right)^{2}}= \\
=\frac{524343,67 * 42,8487-5012,5 * 4390,3718}{50 * 524343,67-(5012,5)^{2}}=0,4219 \\
\mathrm{a} 1=\frac{\Delta \mathrm{a} 1}{\Delta}=\frac{\mathrm{n} \sum \mathrm{Yi}_{\mathrm{i}} * \mathrm{GBP}_{\mathrm{i}}-\sum \mathrm{GBP}_{\mathrm{i}} \sum \mathrm{Y}_{\mathrm{i}}}{\mathrm{n} \sum \mathrm{GBP}^{2}-\left(\sum \mathrm{GBP}_{\mathrm{i}}\right)^{2}}= \\
=\frac{50 * 4390,3718-5012,5 * 42,8487}{50 * 524343,67-(5012,5)^{2}}=0,0043
\end{gathered}
$$

The function, modeling dependence of the value of the rate of US Dollar to Euro (Yi $)^{\text {Euro }}$ on dynamics of index of the rial GDP of the United states has the following form:

$$
Y i^{\text {Eur }}=a 0+a 1 * G B P_{i}=0,4219+0,0043 * G B P_{i}
$$

The simplest system of correlation relationship is a linear relationship between two signs the pair linear correlation. Its practical importance consists in the fact that there is a system in which among the factors influencing the resultant sign one important factor stands out which basically determines the variation of resultant sign (Hamilton J.D., 1994). To determine the dependence of the rate of US dollar to the main world currencies on the dynamics of the USA GDP we will calculate the coefficient of the pair linear correlation with the following formula:

$$
\text { cor }=\frac{\mathrm{n} \sum \mathrm{Yi}^{*}{ }^{\mathrm{GBP}} \mathrm{i}-\sum \mathrm{GBP} \sum \mathrm{Yi}_{\mathrm{i}}}{\sqrt{\left(\mathrm{n} \sum \mathrm{GBP}^{2}-\left(\sum \mathrm{GBP}_{\mathrm{i}}\right)^{2}\right)^{*}\left(\mathrm{n} \sum \mathrm{Yi}^{2}-\left(\sum \mathrm{Y}_{\mathrm{i}}\right)^{2}\right)}}
$$

Linear correlation coefficient is within the range from of from 0 to 1 . When the cor $=0$, any dependence of $\left(\mathrm{Y}_{\mathrm{i}}\right)$ of the indicator on the factor sign $\left(\mathrm{GBP}_{\mathrm{i}}\right)(\mathrm{i}=1,2, \ldots \mathrm{n})$ is absent. When $\mathrm{K}=1$, there is a functional dependence. When $0.3<=$ cor $<=0.7$ - the relationship is average. When the linear correlation coefficient is less than 0.3 the closeness of the relationship is considered weak, when Cor is $>0.7-$ it is strong (Gulyaeva O.A., 2008). 
By using the data given in the table 3, let's calculate the coefficient of pair linear correlation of dependence of the rate of the US dollar to Euro(Yi ) on the dynamics of GDP ${ }^{\text {Eur }}$ (GBPi):

$$
\begin{gathered}
\operatorname{cor}=\frac{\mathrm{n} \sum \mathrm{Yi}^{*} \mathrm{GBP}_{\mathrm{i}}-\sum \mathrm{GBP} i \mathrm{Yi}_{\mathrm{i}}}{\sqrt{\left(\mathrm{n} \sum \mathrm{GBP}^{2}-\left(\sum \mathrm{GBP}_{\mathrm{i}}\right)^{2}\right)^{*}\left(\mathrm{n} \sum \mathrm{Yi}^{2}-\left(\sum \mathrm{Y}_{\mathrm{i}}\right)^{2}\right)}}= \\
=\frac{50 * 519632,3027-602288,4^{*} 42,8487}{\sqrt{\left(50 * 7550028534,3-602288,4^{2}\right)^{*}\left(50 * 37,85-42,8487^{2}\right)}}=0,1911
\end{gathered}
$$

The coefficient of pair linear correlation cor $<0.3$ (cor $=0,1911)$.

By using the data given in the table 4, let's calculate the pair linear correlation coefficient of dependence of the value of the US dollar to Euro rate (Yi ) on the dynamics of index of real GDP ${ }^{\text {Eur }}(\mathrm{GBPi}$ ):

$$
\begin{gathered}
\operatorname{cor}=\frac{\mathrm{n} \sum \mathrm{Yi}_{\mathrm{i}}^{*} \mathrm{GBP}^{-}-\sum \mathrm{GBP} \sum \mathrm{Yi}_{\mathrm{i}}}{\sqrt{\left(\mathrm{n} \sum \mathrm{GBP}^{2}-\left(\sum \mathrm{GBP}_{\mathrm{i}}\right)^{2}\right) *\left(\mathrm{n} \sum \mathrm{Yi}^{2}-\left(\sum \mathrm{Yi}_{\mathrm{i}}\right)^{2}\right)}}= \\
=\frac{50 * 4390,3718-5012,5 * 42,8487}{\sqrt{\left(50 * 524343,67-5012,5^{2}\right) *\left(50 * 37,85-42,8487^{2}\right)}}=0,6041
\end{gathered}
$$

The coefficient of pair linear correlation $0.3<\operatorname{cor}<0.7$ ( $\operatorname{cor}=0,6041$ ).

\section{Discussion}

It is important to say that scientists and specialists actively discus the problems of modeling of currency rates on the basis of the complexity of modern macroeconomic sistuatsii (Panilov M.A., 2008; Gulyaeva O.A., 2008). The presented approaches deserve attantion because they enable to use the developed models not only taking into account the particular domestic economic situation, but also in the condition of the global financial and economic crisis. Moreover, they can form the basis of predicting the dynamics of currency exchange rates, exports, imports, and the inflow/outflow of the capital.

\section{Conclusion}

Thus, the present study analyzed the influence of the dynamics of the GDP of the United States and the index of real GDP of the United States of the value of the US dollar to the euro rate, developed the mechanism of determination of extent of influence of USA GDP on the value of the US dollar to Euro rate during the period of from January 1, 1999 to April 1, 2011.

The mechanism of determination of the extent of influence of the dynamics of the USA GDP on the value of the rate of US dollar to European currency was developed.

On the basis of the number values of the currency exchange rate of the US dollar to Euro, as well as the number values of the dynamics of the USA GDP and an index of real USA GDP, the coefficients of equation of dependence of the US dollar rate on the value of the USA GDP and the index of real GDP of the Unites States were calculates, the linear function that models the dependence of the value of the dollar US to the Euro rate was developed.

The article the extent of influence of the dynamics of the USA GDP and an index of real USA GDP on the value of the US dollar to Euro rate was determined, as well as the parameters of linear functions, modeling the dependence of the US dollar to Euro rate on the dynamics of the USA GDP and an index of real USA GDP were calculated.

This made it possible to develop the model of the linear dependence of the value of US dollar to Euro rate on the dynamics of the USA GDP and an index of real USA GDP and to calculate the coefficient of pair linear correlation characterizing the closeness of their dependence.

However, it should be noted that further improvement of the tools of forecasting and analytical assessments of the dynamics of currency exchange rates in order to develop regulatory measures of currency policy (Shvajko P., 
2002), providing reduction of macroeconomic instability at the national and supranational levels is of significant practical importance. To solve these problems it is necessary to continue the development and substantiation of mathematical economic models that take into account the widest possible range of macroeconomic aggregates and make it possible to quantify the dynamics of equilibrium currency exchange rates of the main world currencies depending on changes in fundamental factors. In addition, it is necessary to provide such modeling of the rate dollar to other national currencies as well.

Acknoledgements. The authors would like to thank the staff of the State Research Institute of System Analysis of the Accounts Chamber of the Russian Federation and personally the director - Vladimir Ivanovich Shchedrov for their help and support to prepair this article.

\section{References}

Aleksandrovich, J. A. (2005). Econometric analisis of the main macroeconomic indicators time series. The economic bulletin of Belarusian economics ministery researth institute, 3, 3-23.

Balatsky, E. (2010). Factors of exchange rates formation: the pluralism of patterns, theories and conceptions. Retrieved from http:// capital-rus.ru/articles/article/180954

Balatsky, E.V. (2005). The model the dynamics of the "dollar / euro" rate. The Economist, 9, 75-81.

Bendat, J., \& Peirsol, A. (1989). Application analysis of random data (p. 540), M.: Mir.

Bogoviz, A. V. (2013). Modeling the Labor Process One of the Tasks of Strengthening of Positive Trends in the Economic Growth of the Industrial Enterprises of the Region. World Applied Sciences Journal, 8(25), $1222-1225$.

Buglaev, V. B., \& Liventsev, N. N. (1998). International Economic Relationships (p. 159). M.: Finance and Statistics.

Fedoseyev, V. V., Garmash, A. N., \& Orlova, I. V. (2005). Economic and mathematical methods and applied models: education guidance for HEIs. M.: UNITY.

Grishin, A. F., Kotov-Darty, S. F., \& Ygunov, V. N. (2005). Statistical models in economics (p. 344). Rostov-on-Don: PHOENIX.

Gulyaeva, O. A. (2008). Currency risk management on the basis of prognostic analysis of exchange rates by fractal methods (p. 27).

Hamilton, J. D. (1994). Time Series Analysis. Princeton University Press.

Ivanter, A., \& Peresetsky, A. (1999). The development of the state bond market. Working paper series, 99/06, May.

Johansen, S. (2000). Modelling of Cointegration in the Vector Autoregressive Model. Economic Modelling, 17, 359-373. http://dx.doi.org/10.1016/S0264-9993(99)00043-7

Keynes, J. M. (1999). The General Theory of Employment, Interest and Money (p.351). M. Helios APB.

Kravtsov, M. A., \& Miksjuk, S. F. (2005). Mathematical modeling of the macroeconomic processes. Science works of Belarusian economics ministery researth institute.

Kryukov, P. A. (2011). Methodology of modeling of the dynamics of the exchange rate. Economics, management, finance: Materials of the international. scientific. conf. Perm: Mercury.

Kryukov, P. A., \& Kryukova, V. V. (2011). Forecasting of the exchange rate on the basis the factor scaling. Bulletin of the Kuzbass State Tech. Unic, 1, 118-127.

Litinsky, D. S. (2003). Statistical forecasting for building effective trading strategies in the currency market. $\mathrm{PhD}$ thesis. Moscow.

Malihin, V. I. (1999). Financial Mathematics (p. 247). M.: UNITY. International economic statistics. Electronic Resource. Retrieved from http://www.statinfo.biz/HTML/M128F6963A483 5L1.aspx

Muraviev, D. G. (2006). Mathematical methods of development and evaluation of trade strategies in the interbank currency market Forex. PhD thesis. Samara.

Oskorbin, N. M. (1989). Some Aspects of Optimization of Decision Support System. Volume of Abstracts International School: Seminar Optimization Methods and Their Applications. Baika.

Panilov, M. A. (2008). Development of the new complex approach to equilibrium exchahge rate analisis. Internet Journal ATiSO. Retrieved from http://www.e-rej.ru/Articles/2008/Panilov/pdf. 
Panilov, M. A. (2009). Economic modeling of the dynamics of the exchange rate. $\mathrm{PhD}$ thesis. Moscow.

Perron, P. (1997). Further evidence on breaking trend function in macroeconomic variables. Journal of econometrics, 80, 355-385. http://dx.doi.org/10.1016/S0304-4076(97)00049-3

Pugel, T. A., \& Lindert, P. H. (2003). International Economics (p. 799). M.: Business and Service.

Shelobaev, S. I. (2005). Economic and mathematical methods and models (p. 285). M.: UNITY.

Shvajko, P. (2002). Econometric models for analysis and forecasting primary market capacity of the state obligations. The Economic Bulletin (ECOVEST), 2, 111-153.

\section{Note}

Note 1. International economical statistics. Digital resourse. Access mode: http://www.statinfo.biz/HTML/M128F6963A4835L1.aspx

\section{Copyrights}

Copyright for this article is retained by the author(s), with first publication rights granted to the journal.

This is an open-access article distributed under the terms and conditions of the Creative Commons Attribution license (http://creativecommons.org/licenses/by/3.0/). 